\section{"A Cohort of Pirate Ships": Biomedical Citizen Scientists' Attitudes Toward Ethical Oversight}

\author{
MEREDITH TREJO (D)
}

ISABEL CANFIELD (D)

WHITNEY BASH BROOKS (D)

ALEX PEARLMAN (D)

CHRISTI GUERRINI D

*Author affiliations can be found in the back matter of this article

\title{
] $\mathrm{u}[$ ubiquity press
}

CORRESPONDING AUTHOR:

\section{Christi Guerrini}

Baylor College of Medicine, US

guerrini@bcm.edu

KEYWORDS:

citizen science; biohacking; DIY biology; community biology; research ethics; Institutional Review Board

TO CITE THIS ARTICLE: Trejo, M, Canfield, I, Brooks, WB, Pearlman, A and Guerrini, C. 2021. "A Cohort of Pirate Ships": Biomedical Citizen Scientists' Attitudes Toward Ethical Oversight. Citizen Science: Theory and Practice, 6(1): 15, pp. 1-15. DOI: https://doi. org/10.5334/cstp.360 


\section{BACKGROUND}

Although the idea of citizen science is not new, in recent decades, it has become a popular approach to research. That approach generally describes the meaningful involvement of members of the public-known as citizen scientists-in the research process. Citizen scientists contribute to research in personal rather than professional capacities and might not have advanced scientific training relevant to the projects they support (Eitzel et al. 2017).

There are examples of citizen science projects in many scientific disciplines, including ecology, astronomy, biology, and medicine (Bonetta 2009). The biomedical citizen science landscape in particular is diverse and encompasses projects with various objectives, organized according to a wide range of designs, and taking place in traditional and nontraditional settings that include participants' homes and community laboratories (Fiske et al. 2019; Wiggins and Wilbanks 2019). Borrowing from other citizen science typologies, these projects can be categorized by the identities and contributions of participants as: (1) top-down activities that are designed and controlled by institution-based scientists with minimal to no input from citizen scientists; (2) collaborative activities that are designed and controlled by institution-based scientists with robust input from citizen scientists, who also help to execute the research; and (3) bottom-up activities that are designed, controlled, and executed by citizen scientists with minimal to no input from institution-based scientists (Aungst, Fishman, and McGowan 2017; Fiske et al. 2019). Some examples of bottom-up biomedical citizen science projects include an online platform for individuals to publicly share their genotyping results and phenotypic information for personal exploration and research use; a community laboratory project to sequence the genome of a cuttlefish; a three-person effort to reverse engineer a gene-therapy drug; a collaboration involving multiple community laboratories to develop a process for generic manufacture of insulin; and a citizen science collaborative involving individuals self-manufacturing and self-injecting putative vaccines (bioCURIOUS n.d.; Greshake et al. 2014; Gallegos et al. 2018; Guerrini et al. 2020a; Talbot 2020).

Reflecting the diversity of the biomedical citizen science landscape, participants have described their activities or communities according to many different terms, including biohacking, community science, and do-it-yourself (DIY) biology (Trejo et al. 2021) (Figure 1). Grinders-a term that describes body modification enthusiasts who implant themselves with cybernetics in hopes of enhancing their senses and other capabilities (Mallonee 2017; Pearlman 2017) —and lifehackers - a term that describes individuals who track their health data and might adjust their behaviors to understand the effects (Wexler 2017) - are also viewed by some as participants in this landscape.

In recent years, United States (US) policy makers have made important investments in citizen science. The National Institutes of Health (NIH) formed a working group in part to facilitate the incorporation of citizen science methodologies into biomedical research (Theisz, Couch, and Gillanders 2016), and the National Cancer Institute launched a Biomedical Citizen Science Hub that provides online tools for communicating about and collaborating on projects (NCI n.d.).

At the same time, policy makers are aware that involving members of the public in the execution of research presents ethical challenges that require attention. One objective of the NIH working group, for example, is to investigate the ethical, legal, and social implications of research that uses citizen science methods (Theisz, Couch, and Gillanders 2016), and in 2015, the NIH hosted a two-day workshop focused on these issues (NHGRI 2015). In 2017, the National Science Foundation funded a working group to identify and prioritize ethical concerns in citizen science (Rasmussen 2017). More recently, the Woodrow Wilson International Center for Scholars, a policy forum supported by Congress, conducted a workshop that involved identifying ethical and governance challenges encountered by individuals conducting their own health research (Kuiken, Pauwels, and Denton 2018; Pauwels and Denton 2018).

In all of these forums, the ethical oversight of bottomup biomedical citizen science activities has been identified as a unique concern. Although many of these activities might be considered relatively safe-for example, altering the genomes of bacteria to make them glow (Lang 2013) or studying the effect of different vitamin regimens on one's homocysteine levels (Swan et al. 2010)_others are likely associated with elevated risk of harm-for example, subjecting oneself to unregulated interventions, such as homemade gene therapies (Lussenhop 2017).

A growing number of observers have considered the application of traditional research ethics norms to these activities (Vayena and Tasioulas 2013a; Rothstein, Wilbanks, and Brothers 2015; Aungst, Fishman, and McGowan 2017; Guerrini et al. 2018; Fiske et al. 2019; Rasmussen 2019; Wiggins and Wilbanks 2019). For traditional research studies, ethical oversight is usually mandated by some combination of the Federal Policy for the Protection of Human Subjects (Common Rule) and US Food and Drug Administration (FDA) regulations (CFR 2019). Both regulations require institutional review boards (IRBs) to evaluate research protocols according to ethical principles and ensure that participants provide their informed consent. But the Common Rule applies only to federally funded or supported studies involving human subjects or their identifiable data or biospecimens, and 


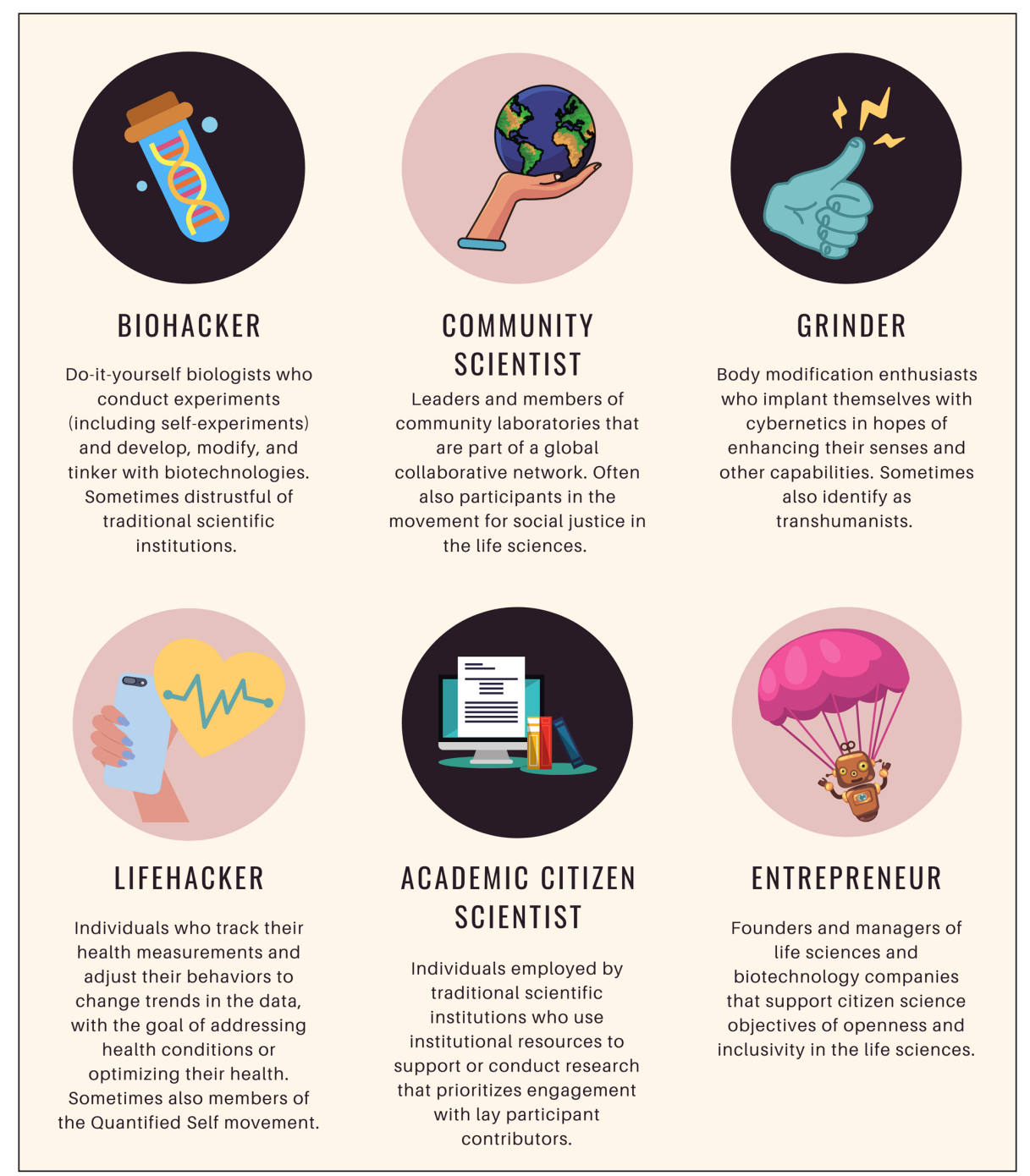

Figure 1 Major biomedical citizen science identities.

the FDA's human research subject regulations apply only to clinical investigations regulated by the agency. Topdown and collaborative citizen science projects generally comply with the Common Rule and FDA human research subject protections because they involve scientists working in traditional scientific settings (such as government, academic, or industry laboratories) where compliance with ethical guidance is mandatory and monitored. Bottom-up biomedical citizen science activities, however, might be conducted with no input from institution-based scientists, are usually not federally funded or supported, and might not qualify as FDA-regulated investigations. Many of these activities are therefore outside the reach of federal ethics review requirements, creating what has been called an ethics gap in citizen science (Rasmussen 2017).

Biomedical citizen science leaders appreciate this gap and have worked to address it through the development of codes and consensus statements. One of the first efforts of DIYbio.org, which organized in 2008 to promote biomedical citizen science, was to develop codes of ethics for North American and European practitioners (DIYbio 2011). More recently, project and community laboratory leaders from around the world participated in engagement exercises at the Global Community Bio Summit that resulted in a consensus document of ethical principles to guide their work (GCBS 2019a).

Further, some biomedical citizen scientists have expressed interest in voluntarily subjecting their projects to ethical oversight. As a practical matter, some sort of independent ethical oversight must be procured by biomedical citizen scientists who aim to publish their work in journals that require it (Stone 2013). The problem is that bottom-up biomedical citizen scientists who would like to participate in ethical oversight do not usually have access to a research institution's IRB. Many also might not be able to afford the review fees charged by independent, forprofit boards that have in the past indicated a willingness to review citizen science projects (Stone 2013). 
But more fundamentally, the procedures that IRBs utilize and the considerations that they emphasize may not align with the ethos and expectations of biomedical citizen scientists. IRB review was designed several decades ago to help research institutions protect human subjects in studies designed and executed by their employeescientists (National Commission 1979). It is far from clear that IRB review is a useful oversight mechanism for research activities designed and executed by citizen scientists outside of institutional settings. For example, one of the three ethical principles that guide IRB review-respect for persons-is usually operationalized as a requirement to obtain informed consent from research subjects. But when citizen scientists are both executing and serving as the subjects of research, it is not clear who should provide consent or how to ensure that it is sufficiently informed (Rasmussen 2021).

Recognizing these issues, several new mechanisms of ethical oversight for biomedical citizen science have been proposed. One model involves a crowdsourced review process in which citizen ethicists or citizen review boards conduct nonbinding ethical assessments of research protocols and post their opinions online (Vayena and Tasioulas 2013b). According to an expert consultation model, ethicists and other experts provide guidance to citizen scientists similar to the online program "Ask a Biosafety Officer," hosted by DIYbio.org for several years (Kuiken, Pauwels, and Denton 2018). Alternatively, community-based committees might provide ethics education and conduct ethical review of projects (Kuiken, Pauwels, and Denton 2018).

Other than an online platform for biomedical citizen scientists conducting self-interventions that tried out a form of crowdsourced review (DIYgenomics 2014), to our knowledge, none of these models has yet been implemented in a systematic or sustained manner, so there is limited information about citizen scientists' perspectives on or experiences with them. However, biomedical citizen science groups have tested other nontraditional mechanisms of ethical oversight and reflected on these efforts. Among them, a group known as Citizen Science Belleville registered its own IRB that follows different procedures than those followed by traditional IRBs. For example, to promote transparency, the board publishes detailed decisions (CSB 2016; Santos-Lang 2019).

Departing from the external processes that typically characterize IRB review, 21 participants in a selfexperimentation study recently tested a system of ethical oversight comprising exercises of ethical self-reflection (Grant, Wolf, and Nebeker 2019). Those exercises included discussion of study risks, risk-management strategies, and potential benefits in group webinars and individual meetings, and they were described as a positive experience for the participants.

Unrelated to specific oversight models, researchers are also beginning to collect data on stakeholder opinions relevant to ethical oversight of unregulated research, including biomedical citizen science projects. For example, in the context of a study focused on unregulated mobile health (mHealth) research, Beskow et al. (2020) conducted interviews with 41 individuals representing four stakeholder groups-patient and research participant advocates; researchers; legal and policy professionals; and mobile app and device developers-about the advisability of external ethical oversight and attitudes regarding how and by whom oversight should occur. Thirteen interviewees were researchers who used mHealth technologies in their studies and were defined to encompass independent researchers and citizen scientists. Over $90 \%$ of interviewees believed unregulated researchers should seek out independent ethical oversight, and some endorsed alternatives to IRBs that included mechanisms for obtaining informal feedback from experts.

All of these efforts have contributed to understanding perspectives on ethical oversight of specific biomedical citizen science activities and experiences with distinct models. To our knowledge, however, no study has sought to capture ethical priorities and oversight preferences of biomedical citizen scientists participating in various projects. These empirical data are useful in developing solutions to the problem of the ethics gap in citizen science because they provide a basis for evaluating the likely effectiveness and acceptability of specific features of oversight mechanisms from the perspectives of those whose projects would be reviewed. Here, we report data from qualitative interviews with 35 stakeholders in bottomup biomedical citizen science from six countries on four continents focused on understanding their attitudes toward ethics and ethical oversight of their work. Based on these data, we consider whether six oversight mechanisms proposed in the literature or considered by citizen science groups align well with the ethical priorities and preferences of diverse biomedical citizen science communities.

\section{METHODS}

In fall 2019, we conducted in-depth qualitative interviews with individuals engaged in biomedical citizen science projects at two conferences: Biohack the Planet, held in Las Vegas, NV, which is a conference "run by BioHackers, designed for BioHackers, with talks solicited from BioHackers" (Kamau 2017), and the Global Community Bio Summit, held in Cambridge, MA, which is "a space for the global community of 
DIY biologists/community biologists/biohackers/biomakers and members of independent and community laboratories to convene, plan, build fellowship, and continue the evolution of our movement" (GCBS 2019b). Whereas Biohack the Planet tends to attract citizen scientists who work independently in home laboratories, the Bio Summit is geared toward citizen scientists who work in community laboratories and other nontraditional laboratory settings. We conducted interviews at both meetings in an effort to capture diverse opinions and experiences.

Before each conference, potential candidates were identified from published lists of conference attendees, with input from one author (AP) who is a veteran attendee of both conferences and was a consultant to this study. To be considered for inclusion, each candidate was required to be at least 18 years old; speak fluent English; and attend one of the conferences. Three authors (MT, CG, IC) conducted the interviews using a semi-structured interview guide, which included questions relevant to the interviewee's attitudes about, preferences for, and experiences with ethics, ethical oversight, and six oversight mechanisms. (All mechanisms were not covered during every interview owing to time constraints.) Interviews were recorded with permission and professionally transcribed. Each interviewee was asked to verbally consent at the start of the interview and was offered a $\$ 75$ gift card at the end of the interview. The mean interview length was 50 minutes.

Four authors (MT, CG, WB, IC) developed a preliminary codebook based on analysis of two interview transcripts. The preliminary codebook was pilot tested and refined as a result of that process. Each transcript was then independently coded according to the final codebook by different combinations of two of the same four authors. Finally, coded reports were reviewed by all authors to identify salient themes and to organize the data.

The study was designed, analyzed, and reported consistent with the Consolidated Criteria for Reporting Qualitative Research (COREQ) (Tong, Sainsbury, and Craig 2007). Additional details regarding methods can be found in Supplemental File 1: Methods.

\section{RESULTS}

Results are reported as follows: (1) descriptive characteristics of interviewees; (2) ethical priorities; (3) attitudes relevant to ethical conduct of research; (4) preferences for features of ethical oversight; (5) opinions of select ethical oversight models; and (6) barriers to implementation. Although some interviewees chose to participate on a nonconfidential basis, no interviewee is identified by name. Rather, to avoid any bias from consideration of identified versus de- identified data, quoted information is attributed to each interviewee using an assigned number.

\section{DESCRIPTIVE CHARACTERISTICS}

Forty-three individuals were invited to participate in an interview and thirty-five individuals participated, for a response rate of $81 \%$. Thirteen individuals were recruited by snowball sampling. Interviewees described various kinds of engagement in biomedical citizen science that included leading, facilitating, participating in, advising, consulting with, and studying bottom-up projects, as well as managing community laboratories. Descriptive characteristics of interviewees, who were residents of six countries on four continents, are set forth in Table 1. Details regarding candidates who declined interviews are set forth in Supplementary File 2: Decliners.

\begin{tabular}{|c|c|}
\hline CHARACTERISTIC & N (\%) \\
\hline \multicolumn{2}{|l|}{ Gender } \\
\hline Male & $21(60 \%)$ \\
\hline Female & 11 (31\%) \\
\hline Gender non-conforming & $1(3 \%)$ \\
\hline Declined to answer & $2(6 \%)$ \\
\hline \multicolumn{2}{|l|}{ Age } \\
\hline 18-19 & $1(3 \%)$ \\
\hline $20-29$ & $9(26 \%)$ \\
\hline $30-39$ & $12(34 \%)$ \\
\hline $40-49$ & $11(31 \%)$ \\
\hline Declined to answer & $2(6 \%)$ \\
\hline \multicolumn{2}{|l|}{ Residence $^{+}$} \\
\hline US Northeast & $10(29 \%)$ \\
\hline US Midwest & $1(3 \%)$ \\
\hline US South & $6(17 \%)$ \\
\hline US West & $9(26 \%)$ \\
\hline International & $6(17 \%)$ \\
\hline Multiple residences & $2(6 \%)$ \\
\hline Declined to answer & $1(3 \%)$ \\
\hline \multicolumn{2}{|l|}{ Conference attended } \\
\hline Biohack the Planet only & $15(43 \%)$ \\
\hline Bio Summit only & $17(49 \%)$ \\
\hline Both & $3(9 \%)$ \\
\hline
\end{tabular}

Table 1 Characteristics of interviewees $(N=35)$.

Percentages might $\neq 100 \%$ due to rounding.

+ US regions defined by US Census Bureau. 


\section{ETHICAL PRIORITIES}

All interviewees were probed about ethical priorities in biomedical citizen science, which were defined as ethical issues or considerations important to their work or to the citizen science communities in which they participated or that they observed. Interviewees described ten priorities: autonomy, consent, safety, community, respect, equality, diversity, education, altruism, and good science.

A frequently described priority was autonomy. Some interviewees conceptualized autonomy as freedom from requirements and expectations associated with traditional scientific institutions. Others viewed autonomy vis-à-vis their peers in nontraditional science spaces. As one interviewee explained, biomedical citizen science communities are like a "a cohort of pirate ships"-fiercely independent and characterized by distinct cultures and norms (021).

A third group focused narrowly on bodily autonomy, described as the "right to do whatever you want with your own body unless it's harming anyone else" (014). Bodily autonomy was cited as an ethical justification for selfexperimentation, self-testing of therapeutic interventions, and self-augmentation, and it was frequently emphasized by interviewees identifying as grinders. While grinder communities discourage members from engaging in activities associated with likely risk of serious harm, such as inserting implants without proper sterilization procedures, self-determination remains central to their communities. As one grinder explained,

So if I want to change anything about myself, whether that might be considered something along the lines of mutation today, [or] like body mutilation, like removing a limb, I think that should be, given the right circumstances, someone who can demonstrate that they're in a sane frame of mind, should be able to do that (003).

So described, the obligation to respect another person's autonomy assumes that the person is acting voluntarily and with knowledge of the risks. Although it was recognized that some biomedical citizen scientists have a higher risk tolerance than the general population, project organizers are still expected to communicate those risks, and in contexts of self-experimentation or implantation, it is expected that participants will research and be prepared to discuss the risks of their activities with peers. One grinder explained that, as a result of the practice of "walk[ing] through all the pieces" and getting "real-time feedback" on a planned project, "in many ways ours is a more robust informed consent" than is obtained in clinical contexts or in traditional studies, where participants just "star[e] at a piece of paper going, 'What does that word mean?'” (019).

Interviewees explained that the ethical priority of informed consent promotes safety, which was described not only as taking action to prevent harm to oneself, but also-and, for some, more importantly - to prevent harm to others or to the environment. Many interviewees complained about a common media narrative that their work is reckless or even intentionally dangerous. But as one interviewee observed, "when you actually spend time with the people in this community, literally, the vast, vast, vast majority are the good guys" who seek to avoid harm (011). Moreover, this narrative ignores the community norms in place that encourage calling out and even ostracizing those perceived to be engaged in "stunt-ish" behavior (030). As one interviewee emphasized, there "is really no support for those kind of people" (004).

The ethical priority of community was described as encompassing obligations to support one another by sharing information and resources, providing encouragement and constructive feedback, and making space for others to become involved. One interviewee described an imperative to "keep watching out for each other [a]nd understand that we're all on the same team" (015). Communityfocused goals also included facilitating collaborations with each other; some interviewees proudly noted their growing network of global collaborations. However, enthusiasm for collaboration was not synonymous with centralization or standardization. Most interviewees preferred local control of projects and local development and enforcement of norms.

Related to community was the ethical priority of respect, which many interviewees described as valuing and showing appreciation for other people in the community and their ideas. One interviewee discussed "trying to understand the different skills and the different lenses that different people will bring to a project or a collaborative effort" (021), while another said it was having "the ability to disagree with someone and still work with them" (018). However, others described respect for "the power of the technology" and tools they used and the environmental impacts of their work (033).

Interviewees endorsed three priorities that expressed commitments to inclusivity. First, interviewees emphasized the importance of equality in their communities, which was described as equal access to opportunities in science, especially by marginalized groups. Closely related to equality was diversity. As one interviewee explained, citizen science presents an opportunity to "become an inclusive community from the get-go, rather than be trying to repair systems" in traditional scientific institutions that can be discriminatory and exclusionary (025). For many interviewees, equality and diversity drove their 
commitments to education, described by one interviewee as "bring[ing] science outside of the ivory tower so that more people can see it, can live it, can practice it, can benefit from it" (021).

More broadly, interviewees emphasized that altruism, or "doing something for the betterment of humanity" and finding ways to alleviate suffering, is central to their work (026). For example, some interviewees explained that they felt compelled to address environmental problems or disparities in access to medical or scientific advancements that might be overlooked or perpetuated by the establishment.

Finally, regardless of who participates in citizen science or for what reasons, it was important to many interviewees that the work constitute good science. Operationalized as robust documentation, rigorous methods, and transparent results, good science was viewed as an ethical priority because it facilitates safe, valid, and reproducible research. So described, good science promotes open science. As one interviewee from a community laboratory explained, "if you're really wanting to share, be open, accessible, you have to have really good documentation" (034). Interviewees also noted that it would be impossible to successfully collaborate with each other if they did not share all aspects of their work.

\section{GENERAL ETHICS ATTITUDES}

When probed about their attitudes toward the utility of ethical reflection in scientific research, interviewees described a common desire to act ethically and explained how ethical conduct of research is currently promoted through informal mechanisms. According to one interviewee, frequent conversation with community members about project-related questions and concerns itself serves as a form of ethical oversight: "[W]e always talk to your peers about it. And then you already have a non-formal ethics board" (006). Others explained that they engaged in self-reflection, sometimes as a complement to peer-to-peer conversations, to identify and work though ethical issues. One interviewee explained that this process includes thoughtful consideration of questions such as "What are your intentions in doing this? ... And what would your friends say?" as well as consideration of possible downstream effects of the research (015).

But some interviewees had reservations about incorporating more formal review mechanisms into their processes based on their association of ethics with punishment-based rules and permissions systems. One interviewee explained that their community has "definitely struggled with the idea of ethics at all because we always think of it as submitting for permission," which can be offensive and overly restrictive (016). However, one biohacker suspected that these and other skeptical attitudes will change as their communities "grow up:"

These people, ... they're like, "Yeah. Ethics is unnecessary. It stifles creativity." And I'm like, "Yes, yeah. This is exactly like having a conversation about a condom [with] a five year old." Because it doesn't actually matter. Like, "Ew! Ethics are gross.” I'm like, "Yeah, well wait until you grow up a little bit and then you're going to be like, 'Wow, I should put that ethics on my dick"” (002).

For some interviewees, negative attitudes toward ethical oversight were grounded in experiences working in traditional scientific institutions that included observations and perceived institutional tolerance of unethical conduct. Mechanisms intended to prevent such misconduct in traditional scientific settings, including IRBs, were perceived to fall short of addressing these ethical lapses: "A lot of bioethics, in terms of institutional review boards and things like that, are more worried about protecting the institution legally ... than they are about actually doing what may be ethical" (018).

Finally, we probed interviewees about their attitudes toward the role of regulation in promoting the ethical conduct of research. Although anti-regulatory and antigovernment attitudes were common, most interviewees described their desire to comply with relevant regulations. Compliance can be difficult, however, when regulations are difficult to understand. One biohacker-turned-entrepreneur described their experience with regulatory compliance as follows: "It is a clusterfuck. I have no clue where to even start. I have to hire a very expensive lawyer to figure it out" (004). Moreover, several grinders did not prioritize legal compliance where it was perceived to interfere with rights to bodily autonomy. As one explained:

I put these implants in whether it's legal or not.... I own my body, whether somebody else likes it or not. I'm not waiting for the laws to be the correct way to be. I'm going to just exercise what I feel is my fundamental right whether or not it's recognized appropriately (015).

Interviewees also generally opposed codifying ethical principles and processes for biomedical citizen science into laws and regulations. They worried that such requirements would be reactive, overly restrictive, and based on a flawed understanding of their activities and intentions. Indeed, several identified a need to increase communication 
between regulators and biomedical citizen scientists to prevent regulatory overreach. As one interviewee put it, "How could you guys make a law for something you don't understand? ... You have no right [to regulate] unless you know" (007).

\section{PREFERENCES FOR OVERSIGHT FEATURES}

Interviewees identified several features of ethical oversight that would be consistent with the ethos of their communities. In particular, there was general consensus that oversight mechanisms should be "culture-built" (012), meaning developed by and for specific communities rather than imposed by external bodies. Bottom-up development not only ensures that oversight is tailored to the community's needs and priorities, it also promotes trust and community "buy-in" (035).

At the same time, many interviewees believed that oversight mechanisms should invite participation by, or at least not intentionally exclude, outside experts. For example, several interviewees acknowledged the value of establishing relationships with bioethicists:

I think you definitely need outside people and maybe someone who's an expert in ethics. It's not that I think people are incapable of doing it on their own if they don't have a PhD in ethics. But there's also a reason why we defer to experts, as they've thought long and hard about something that we frankly haven't (030).

Still, some worried that bioethicists would "want to come in and impose some ethical standard" that the community might not endorse or would result in unfair negative assessments of their activities (011). By contrast, most recognized the potential benefits of partnering with other kinds of experts, such as institution-based scientists and lawyers. For such partnerships to be successful, however, there was consensus that these experts must appreciate the independence and unique cultures of the "pirate ships" populating the biomedical citizen science landscape (021).

Consistent with this framing, there was broad consensus that participation in any ethical oversight mechanism should be voluntary. One interviewee stressed, "[Y]ou can't tell this community they have to do something. You can't" (013). Another interviewee agreed: "[A]ny time you drop the word mandatory in the community bio lab, people will start setting fires" (021). For these reasons, interviewees also generally agreed that the results of oversight should be advisory and intended to empower them to make ethically informed decisions. As an interviewee familiar with many community laboratories explained, "You're never going to, I don't believe, going to get the community to give 'go, no go' power" to reviewers (033). Biohackers were especially opposed to mandatory, rule-based oversight mechanisms, consistent with their self-identity as rulebreakers:

You can build a rule set, but part of my job is exploiting rule sets, right? I'm a biohacker, right? Finding holes in patents, finding loopholes in laws, that's what I do for a living. So if you make a rule, I can figure out a way to break it.... So if you make more rules, all you're going to get is more clever kids breaking rules (002).

Notably, they did not view their rule-breaking activities as inherently unethical on the basis of the view that some rules are motivated primarily by self-interest and are not necessarily ethical in practice.

While many recognized that voluntary oversight mechanisms lack enforcement tools that might be needed to be effective, the decentralized and global nature of biomedical citizen science means that no mechanism will be completely effective in identifying and stopping those whose activities are sure to harm others. Therefore, although at least one interviewee endorsed formal oversight procedures, their reasoning was unrelated to impeding bad actors. Rather, they believed that formality encourages participants to take the process seriously.

Finally, many interviewees explained that oversight mechanisms should take care not to replicate hierarchical and exclusionary structures of traditional scientific institutions. For example, one interviewee involved in a community laboratory expressed concern about oversight mechanisms that might "reproduc[e] the same types of power structures that we're trying to avoid" (028). It was also noted that those structures "don't actually support addressing some of those ethical issues around access, equity, and who participates and who doesn't" that are prioritized by many biomedical citizen science communities (021).

\section{OPINIONS OF SELECT OVERSIGHT MODELS}

Interviewees' opinions of specific oversight models for biomedical citizen science provided further information about the acceptability and feasibility of potential features of ethical oversight. Six models that have been proposed in the literature or considered by citizen science groups were discussed with interviewees: traditional IRB review, expert consultation, community review, crowdsourced review, systematized self-reflection, and codes of ethics (Figure 2).

Table 2 summarizes key advantages and disadvantages of each model from the perspective of interviewees. Briefly, interviewees explained that the use of traditional IRBs to evaluate their work could increase its perceived legitimacy. 


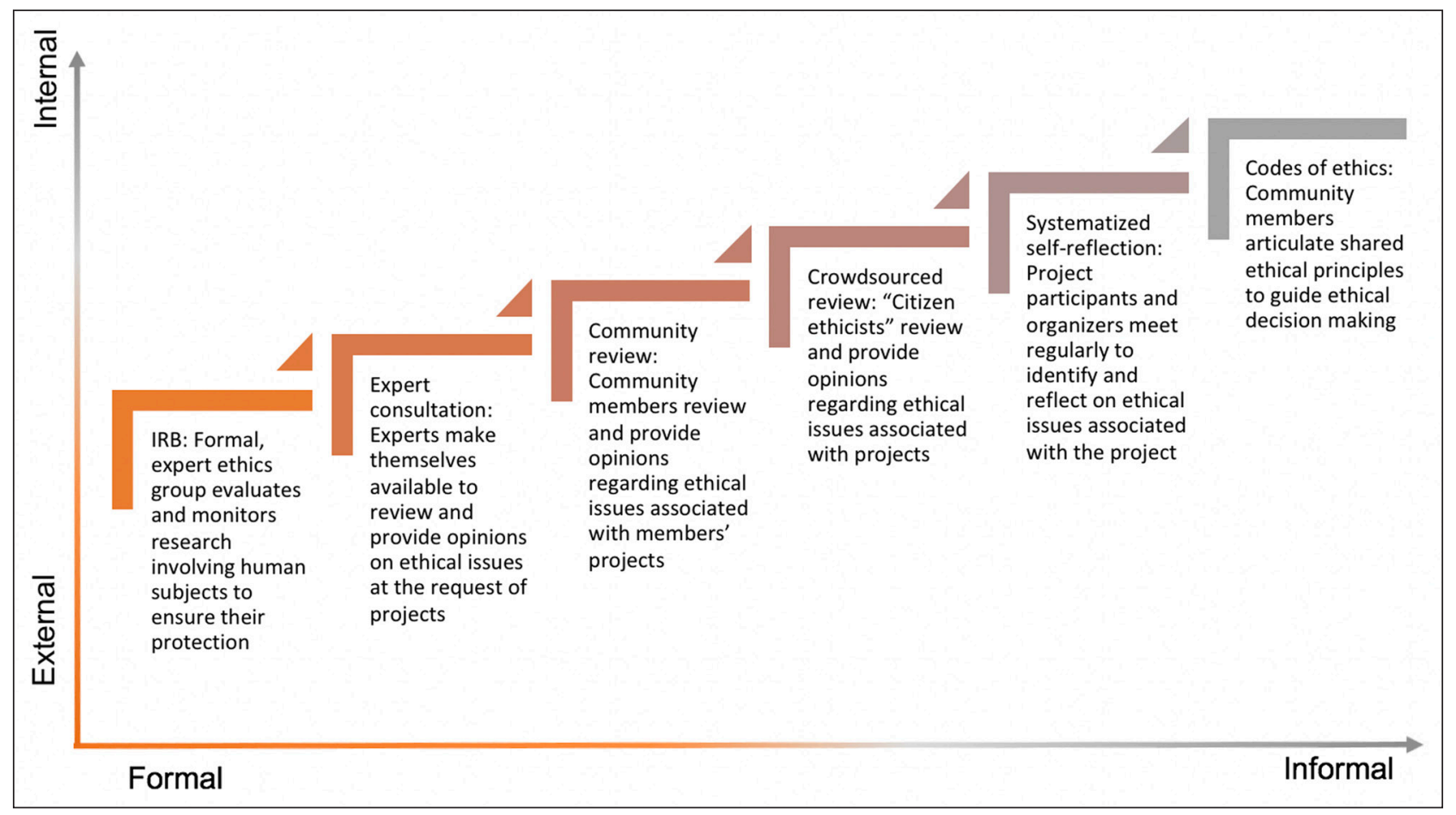

Figure 2 Six ethical oversight models.

\begin{tabular}{|c|c|c|}
\hline OVERSIGHT MODEL & ADVANTAGES & DISADVANTAGES \\
\hline Traditional IRB review & $\begin{array}{l}\text { - Obtain recommendations from experts in the ethical } \\
\text { review of scientific research } \\
\text { - Might increase perceived legitimacy } \\
\text { - Might preempt/mitigate criticisms by demonstrating } \\
\text { serious commitment to ethics review }\end{array}$ & $\begin{array}{l}\text { - Difficulty accessing an established IRB or developing } \\
\text { one's own IRB } \\
\text { - Elitist and hierarchical } \\
\text { - Too formal and time-consuming for low-risk activities }\end{array}$ \\
\hline Expert consultation & $\begin{array}{l}\text { - Obtain recommendations from variety of experts } \\
\text { - Might facilitate mentorships }\end{array}$ & $\begin{array}{l}\text { - Difficulty finding the right experts } \\
\text { - Unclear how to engage experts long term }\end{array}$ \\
\hline Community review & $\begin{array}{l}\text { - Obtain recommendations from peers in community } \\
\text { - Community driven } \\
\text { Might be similar in structure to existing safety review } \\
\text { boards in the community }\end{array}$ & $\begin{array}{l}\text { - Could be elitist and hierarchical depending on who is } \\
\text { allowed to participate } \\
\text { - Resource intensive }\end{array}$ \\
\hline Crowdsourced review & $\begin{array}{l}\text { Obtain feedback from designated peers in community } \\
\text { or outsiders } \\
\text { - Decentralized and not elitist or hierarchical }\end{array}$ & $\begin{array}{l}\text { - Difficulty identifying the right citizen ethicists } \\
\text { - If online, potential for trolling and misunderstanding }\end{array}$ \\
\hline $\begin{array}{l}\text { Systematized self- } \\
\text { reflection }\end{array}$ & $\begin{array}{l}\text { - Elicit reflections from those directly engaged in projects } \\
\text { - Might yield insights for other projects }\end{array}$ & $\begin{array}{l}\text { - Unclear how to manage different ethical opinions } \\
\text { - Resource intensive }\end{array}$ \\
\hline Codes of ethics & $\begin{array}{l}\text { - Identify and communicate shared values } \\
\text { - Community driven } \\
\text { - Useful as a general guide to decision making }\end{array}$ & $\begin{array}{l}\text { - Incapable of answering ethical questions in specific } \\
\text { circumstances }\end{array}$ \\
\hline
\end{tabular}

Table 2 Interviewees' opinions of select ethical oversight models.

However, IRBs were criticized as elitist, hierarchical, and prone to abuses of power, as well as too formal and timeconsuming for many biomedical citizen science activities. It was generally agreed that expert consultation could provide valuable insights and guidance as a "sounding board" for community members (033). But interviewees worried about the difficulty of identifying experts who understand their communities' values and priorities and would engage with them over the long term.

With respect to internal governance models, interviewees noted that advantages of community review include that it is culture-built and can be modeled after 
existing community safety review boards. Depending on the structure, however, it might be elitist or hierarchical and require an unsustainable amount of time and resources. By contrast, interviewees explained that the crowdsourced review model, which invites input from designated peers and non-biased outsiders, is decentralized and not prone to abuses of power. However, concerns were raised about how to select individuals to serve as citizen ethicists, and if reviews are posted online, whether they will provoke trolling and contribute to misunderstanding, which are issues that already plague some communities' online discussion boards.

Interviewees had a generally favorable view of systematized self-reflection because it engages all individuals directly involved in specific projects and might yield insights for other projects. However, this model might be too resource-intensive for specific projects, and interviewees were unsure how differences of ethical opinion would be managed. Finally, while many interviewees believed that codes of ethics are useful in demonstrating their commitment to ethical conduct, one interviewee questioned the value of codes given that they cannot provide specific guidance or answers to questions. Representing an extreme opinion, one interviewee described codes of ethics as "garbage" for the reason that "no one will read [them]" (001).

\section{IMPLEMENTATION BARRIERS}

Although interviewees noted distinct issues with implementing each oversight model, as described above, some common themes emerged. First, several interviewees emphasized the many demands on their time and explained that they were reluctant to spend what little time they had carved out for research on developing or participating in oversight activities. For them, this tradeoff presented "a really frustrating choice" (034). Second, interviewees worried about the costs associated with developing infrastructures for oversight. Explained one interviewee who had relationships with multiple community laboratories, "[T]he reality is, is that the labs are not going to be able to pay for it" (033).

Third, interviewees noted that context matters when it comes to the need for oversight but had difficulty identifying specific activities for which oversight should apply or at least be made available. Although there was consensus that much of the work done in biomedical citizen science communities is low risk and should not require ethical oversight-"I don't need an ethics oversight board for every fucking sixth grade project that one of these guys cranked out," stated one biohacker (002) -interviewees did not know where to draw that line. They also did not agree on whether self-experimentation should be exempt from ethics review on autonomy grounds. Relatedly, many questioned what standards should guide ethical review or reflection given the disparate activities, needs, concerns, and priorities of biomedical citizen science communities. Although there was consensus that oversight should at least aim to avoid harm to others, even this principle was described as open to interpretation. Without standards in place, some interviewees worried about persons responsible for providing ethics review or developing guidance making political or emotional decisions.

Finally, interviewees described governance challenges with implementing any kind of ethical oversight in their communities. Specifically, questions were raised about who should be involved in providing ethics review or developing guidance, what criteria should be used to select those individuals, and who should select them. One interviewee wondered, "[W]ho vets? Who watches the watchmen?" (032). Resolution of these challenges was considered especially complicated given biomedical citizen science communities' commitments to promoting diversity and inclusivity and avoiding the creation of elitist and hierarchical systems.

\section{DISCUSSION}

To our knowledge, this is the first study to probe a global sample of biomedical citizen science stakeholders about their ethical priorities, attitudes toward ethical oversight, and ethical oversight preferences. Interviewees' ethical priorities related to autonomy and inclusivity were endorsed by biomedical citizen scientists in prior studies. (Sanchez Barba 2014; McGowan et al. 2017; Guerrini et al. 2020b). Good science is also consistent with efforts to promote the acquisition of good-quality data in citizen science (Kosmala et al. 2016). More generally, the ethical priorities identified by our study participants align with ethics guidance developed by biomedical citizen science groups, which is not surprising given several interviewees' involvement in those efforts (DIYbio 2011; GCBS 2019a).

In some cases, interviewees' conceptualization of ethical priorities provided a fresh take on those described in the Belmont Report, which provides an analytical framework to guide consideration of ethical issues in US human subjects research (National Commission 1979). For example, the Belmont Report describes respect for persons, operationalized through a requirement to obtain informed consent, as a guiding principle in research ethics. Interviewees also endorsed this principle but viewed it through a lens that emphasizes rights of selfdetermination, so that in some cases, respect for persons might mean allowing them to take risks of harm to self. 
The Belmont Report also describes justice as a guiding principle and interprets it to require equitable selection of subjects and distribution of research benefits and burdens. By contrast, our interviewees conceptualized justice as commitments to the diversity of all participants in scientific knowledge production and equal and open access to the tools and fruits of research. Further, interviewees identified ethical priorities that go beyond those described in the Belmont Report, such as commitments to communities, that might serve to, as Ikemoto (2017, p. 566) observed, "situat[e] science as a tool for social justice." These findings suggest that, depending on the biomedical citizen science project, reliance solely on the Belmont Report (and the Common Rule that builds on it) to guide its ethical review might not be appropriate or sufficient from the perspective of participants (Rasmussen 2019; Rasmussen 2021).

Indeed, given the diversity of the actors and activities in biomedical citizen science, it is clear that there will be no one-size-fits-all solution to the problem of the ethics gap. Nevertheless, interviewees were able to agree on some preferred features. Specifically, they endorsed ethical oversight mechanisms that are voluntary, community-driven, and offer guidance. Conversely, they rejected mechanisms that are mandatory, inflexible, and hierarchical. Triangulating these results with interviewees' opinions of specific oversight mechanisms, the expert consultation and community review models appear to be consistent with the preferences, priorities, and needs of many biomedical citizen sciences communities, especially if participation in these mechanisms is voluntary and they function in advisory capacities. However, systematized ethical reflection might work well for specific projects involving a limited number of participants, and codes of ethics can be useful in establishing general standards of conduct. By contrast, traditional IRB review is generally not practical or trusted, whereas crowdsourced review is likely to be unwieldy if conducted online.

Interviewees' concerns about IRB review in particular are similar to those voiced by investigators using communitybased participatory research (CBPR) approaches. In an interview study, CBPR researchers described frustrations with having their work reviewed by outsiders who might not understand their research contexts, objectives, or ethical concerns (Shore 2007). One interviewee felt traditional IRBs rely on regulations "written originally for particular, non-participatory, more traditional kinds of research, particularly empirically based, quantitative research," and do not translate well to community-based research (Shore 2007, p. 37). In practice, this disconnect can lead to IRBs making determinations that delay or even derail CBPR projects.
In prior research, we reported biomedical citizen scientists' frustration with and distrust of traditional scientific and medical institutions (Guerrini et al. 2020b). Interviewees in this study echoed those sentiments and channeled them into commitments to community-based solutions to ethical oversight that did not recreate oversight mechanisms perceived to be elitist and hierarchical. However, solutions that rely on internal review might be in tension with recommendations that biomedical citizen scientists avoid participating in the review of their own work on grounds that they will not be able to objectively assess its risks and benefits (Rothstein et al. 2020).

Despite their worries about involvement by outsiders, interviewees generally did not oppose-some even welcomed-ethical guidance from independent experts, although they stressed that such experts would need to respect their communities' culture for those partnerships to be successful. In 2018, the Wilson Center brought together regulators, scholars, and biomedical citizen scientists to identify ethical and governance challenges encountered in health self-research (Kuiken, Pauwels, and Denton 2018). Our results support continuation of these relationship-building efforts, especially at the project level. We urge bioethicists in particular to keep an open mind if approached by biomedical citizen science communities and recommend further research to clarify every party's liability and reporting obligations, which might mitigate potential concerns associated with entering such partnerships.

Our findings are subject to several limitations. First, the data are not generalizable to all biomedical citizen scientists or their communities. Second, our interview population was limited to individuals who physically attended at least one of two conferences. Conference attendees might have had more resources or been better connected within and across communities than non-attendees. Further, ethical issues were discussed during scheduled sessions at both conferences. As such, conference attendees may have been more interested in, or might have more deeply considered, the ethical implications of their work compared with non-attendees. Third, although our sample included biomedical citizen scientists from around the world, the majority resided in the United States. As a result, our data likely underrepresent practices and norms that are common outside the United States. Finally, like other studies involving biomedical citizen scientists (Sanchez Barba 2014; Zarate et al. 2016; Guerrini et al. 2020b), the majority of interviewees were male. However, through careful pre-selection of potential candidates and snowball sampling, we sought to maximize diversity and the data reflect a wide range of experiences and perspectives. 


\section{CONCLUSION}

Looking ahead, we support continued investigation of the use of various oversight mechanisms in biomedical citizen science communities and efforts to facilitate collaborations with experts and understanding by regulators and other stakeholders. More generally, we recommend further research of the role and application of ethics in biomedical citizen science settings. Given that traditional research ethics principles and practices do not appear to always translate well to these settings, it might be time to consider the development of new ethical frameworks for biomedical citizen science.

\section{SUPPLEMENTARY FILES}

The supplementary files for this article can be found as follows:

- Supplemental File 1. Methods. DOI: https://doi. org/10.5334/cstp.360.s1

- Supplemental File 2. Decliners. DOI: https://doi. org/10.5334/cstp.360.s2

\section{ETHICS AND CONSENT}

The study protocol was reviewed and approved by the Institutional Review Board of Baylor College of Medicine (H-40925).

\section{FUNDING INFORMATION}

This research was supported by the National Human Genome Research Institute of the National Institutes of Health under Award Number K01 HG009355-S1. The content is solely the responsibility of the authors and does not represent the official views of the National Institutes of Health, the authors' employers, or any institutions with which they are or have been affiliated.

\section{COMPETING INTERESTS}

The authors have no competing interests to declare.

\section{AUTHOR CONTRIBUTIONS}

MT contributed to study design; managed research activities; collected, coded, and analyzed data; contributed to data visualization; prepared the initial manuscript draft; and contributed to manuscript revisions.

IC contributed to study design; collected, coded, and analyzed data; and contributed to manuscript revisions.

WBB contributed to study design; coded and analyzed data; contributed to data visualization; and contributed to manuscript revisions.

AP contributed to study design; analyzed data; contributed to data visualization; and contributed to manuscript revisions.

CG conceptualized the study; supervised research activities; collected, coded, and analyzed data; contributed to data visualization; and contributed to manuscript revisions.

\section{AUTHOR AFFILIATIONS}

Meredith Trejo (D) orcid.org/0000-0003-2719-6050 Baylor College of Medicine, US

Isabel Canfield (iD) orcid.org/0000-0001-9537-8214 Baylor College of Medicine, US

Whitney Bash Brooks (D) orcid.org/0000-0002-3069-5101 Baylor College of Medicine, US

Alex Pearlman (D) orcid.org/0000-0003-4344-0826 Independent Journalist, US

Christi Guerrini (iD) orcid.org/0000-0003-4430-2740 Baylor College of Medicine, US

\section{REFERENCES}

Aungst, H, Fishman, JR and McGowan, ML. 2017. Participatory genomic research: Ethical issues from the bottom up to the top down. Annual Review of Genomics and Human Genetics, 18(1): 357-367. DOI: https://doi.org/10.1146/annurevgenom-091416-035230

Beskow, LM, Hammack-Aviran, CM, Brelsford, KM and O'Rourke, PP. 2020. Expert perspectives on oversight for unregulated mHealth research: Empirical data and commentary. The Journal of Law, Medicine \& Ethics, 48(S1): 138-146. DOI: https://doi.org/10.1177/1073110520917039

bioCURIOUS. bioCURIOUS projects. Available at https://biocurious. org/projects/\#active (Last accessed 10 March 2021).

Bonetta, L. 2009. New citizens for the life sciences. Cell, 138(6): 1043-1045. DOI: https://doi.org/10.1016/j.cell.2009.09.007

Citizen Science Belleville (CSB). 2016. Publication of IRB opinions. Available at https://osf.io/9e3gx/wiki/Publication\%20of\%20 IRB\%200pinions/ (Last accessed 28 February 2020).

DIYbio. 2011. DIYbio codes. Available at https://diybio.org/codes/ (Last accessed 1 June 2020). 
DIYgenomics. 2014. DIYgenomics citizen ethicist review. Available at http://diygenomics.pbworks.com/w/page/53826289/ Ethical_Review (Last accessed 26 February 2021).

Eitzel, MV, Cappadonna, JL, Santos-Lang, C, Duerr, RE, Virapongse, A, West, SE, Kyba, CCM, Bowser, A, Cooper, CB, Sforzi, A, Metcalfe, AN, Harris, ES, Thiel, M, Haklay, M, Ponciano, L, Roche, J, Ceccaroni, L, Shilling, FM, Dorler, D, Heigl, F, Kiessling, T, Davis, BY and Jiang, Q. 2017. Citizen science terminology matters: Exploring key terms. Citizen Science: Theory and Practice, 2(1): 1. DOI: https://doi. org/10.5334/cstp.96

Fiske, A, Del Savio, L, Prainsack, B and Buyx, A. 2019. Conceptual and ethical considerations for citizen science in biomedicine. In: Heyen, NB, Dickel, S and Brüninghaus, A (eds.), Personal Health Science. Wiesbaden: Springer VS. pp. 195-217. DOI: https://doi.org/10.1007/978-3-658-16428-7_10

Gallegos, JE, Boyer, C, Pauwels, E, Kaplan, WA and Peccoud, J. 2018. The Open Insulin Project: A case study for 'biohacked' medicines. Trends in Biotechnology, 36(12): 1211-1218. DOI: https://doi.org/10.1016/j.tibtech.2018.07.009

Global Community Bio Summit (GCBS). 2019a. Community ethics. Available at https://www.biosummit.org/ethics (Last accessed 1 June 2020).

Global Community Bio Summit (GCBS). 2019b. Global Community Bio Summit 3.0. Available at https://www. biosummit.org/2019 (Last accessed 5 March 2021).

Grant, AD, Wolf, GI and Nebeker, C. 2019. Approaches to governance of participant-led research: A qualitative case study. BMJ Open, 9: e025633. DOI: https://doi.org/10.1136/ bmjopen-2018-025633

Greshake, B, Bayer, PE, Rausch, H and Reda, J. 2014. openSNP-A crowdsourced web resource for personal genomics. PLOS One, 9(3): e89204. DOI: https://doi. org/10.1371/journal.pone.0089204

Guerrini, CJ, Majumder, MA, Lewellyn, MJ and McGuire, AL. 2018. Citizen science, public policy. Science, 361(6398): 134-136. DOI: https://doi.org/10.1126/science.aar8379

Guerrini, CJ, Sherkow, JS, Meyer, MN and Zettler, PJ. 2020a. Selfexperimentation, ethics, and regulation of vaccines. Science, 369: 1570-1572. DOI: https://doi.org/10.1126/science. abe1963

Guerrini, CJ, Trejo, M, Canfield, I and McGuire, AL. 2020b. Core values of genomic citizen science: Results from a qualitative interview study. BioSocieties. DOI: https://doi.org/10.1057/ s41292-020-00208-2

Ikemoto, LC. 2017. DIY bio: Hacking life in biotech's backyard. University of California, Davis Law Review, 51: 539-568.

Kamau, WS. 2017. Defining open: Biohack the Planet. O'Reilly, 11 January [online access at https://www.oreilly.com/content/ defining-open-biohack-the-planet/ last accessed 20 July 2020].

Kosmala, M, Wiggins, A, Swanson, A and Simmons, B. 2016. Assessing data quality in citizen science. Frontiers in Ecology and the Environment, 14(10): 551-560. DOI: https://doi. org/10.1002/fee.1436

Kuiken, T, Pauwels, E and Denton, SW. 2018. The rise of the new bio-citizen: Ethics, legitimacy, and responsible governance in citizen-driven biomedical research and innovation workshop report. Available at https://www.wilsoncenter.org/ sites/default/files/7.3.18_chi_workshop-report_1.pdf (Last accessed 20 July 2020).

Lang, D. 2013. DIY synthetic biology: Making your own glowing plants. Make. 16 May [online access at https://makezine. com/2013/05/16/diy-synthetic-biology-making-your-ownglowing-plants/ last accessed 1 July 2020].

Lussenhop, J. 2017. Why I injected myself with an untested gene therapy. BBC News, 21 November [online access at https://www.bbc.com/news/world-us-canada-41990981 last accessed 21 July 2020].

Mallonee, L. 2017. The DIY cyborgs hacking their bodies for fun. WIRED, 8 June [online access at https://www.wired.com/story/ hannes-wiedemann-grinders/ last accessed 20 July 2020].

McGowan, ML, Choudhury, S, Juengst, ET, Lambrix, M, Settersten, RA and Fishman, JR. 2017. "Let's pull these technologies out of the ivory tower": The politics, ethos, and ironies of participant-driven genomic research. BioSocieties, 12(4): 494519. DOI: https://doi.org/10.1057/s41292-017-0043-6

National Cancer Institute (NCI). Biomedical Citizen Science Hub. Available at https://citscibio.org/ (Last accessed 3 July 2020).

National Commission for the Protection of Human Subjects of Biomedical and Behavioral Research. 1979. The Belmont Report: Ethical Principles and Guidelines for the Protection of Human Subjects of Research. Bethesda, MD.

National Human Genome Research Institute (NHGRI). 2015. Trans-NIH workshop to explore the ethical, legal and social implications (ELSI) of citizen science. Available at https://www.genome.gov/event-calendar/Ethical-LegalSocial-Implications-of-Citizen-Science (Last accessed 01 July 2020)

Pauwels, E and Denton, SW. 2018. The rise of the bio-citizen. Washington, DC: Wilson Center.

Pearlman, A. 2017. The ethics of experimentation: Ethical cybernetic enhancements. Medium, 19 June [online access at https://medium.com/@lexikon1/ the-ethics-of-experimentation-ethical-cyberneticenhancements-48f9ad991769 last accessed 12 August 2020].

Rasmussen, LM. 2017. Filling the "ethics gap" in citizen science research: a workshop report. Available at https://www.niehs. nih.gov/research/supported/translational/peph/webinars/ ethics/rasmussen_508.pdf (Last accessed 20 July 2020).

Rasmussen, LM. 2019. Beyond Belmont-and beyond regulations. The American Journal of Bioethics, 19(8): 19-21. DOI: https://doi.org/10.1080/15265161.2019.1619879 
Rasmussen, LM. 2021. Research ethics in citizen science. In: Iltis, AS and Mackay, D (eds.), The Oxford Handbook of Research Ethics. Oxford University Press: Oxford. DOI: https://doi. org/10.1093/oxfordhb/9780190947750.013.36

Rothstein, MA, Wilbanks, JT and Brothers, KB. 2015. Citizen science on your smartphone: An ELSI research agenda. The Journal of Law, Medicine \& Ethics, 43(4): 897-903. DOI: https://doi.org/10.1111/jlme.12327

Rothstein, MA, Wilbanks, JT, Beskow, LM, Brelsford, KM, Brothers, KB, Doerr, M, Evans, BJ, Hammack-Aviran, CM, McGowan, ML and Tovino, SA. 2020. Unregulated health research using mobile devices: Ethical considerations and policy recommendations. The Journal of Law, Medicine \& Ethics, 48(S1): 196-226. DOI: https://doi. org/10.1177/1073110520917047

Sanchez Barba, GA. 2014. We are biohackers: Exploring the collective identity of the DIYbio movement. MSc thesis, Delft University of Technology.

Santos-Lang, C. 2019. Making it easier to make your own IRB, Narrative Inquiry in Bioethics, 9(1): E9-E12. DOI: https://doi. org/10.1353/nib.2019.0025

Shore, N. 2007. Community-based participatory research and the ethics review process. Journal of Empirical Research on Human Research Ethics, 2(1): 31-41. DOI: https://doi.org/10.1525/ jer.2007.2.1.31

Stone, J. 2013. Of citizen science, ethics, and IRBs the view from Science Online. Scientific American, 5 February [online access at https://blogs.scientificamerican.com/ molecules-to-medicine/of-citizen-science-ethics-and-irbs-theview-from-science-online/?print=true last accessed 23 July 2020].

Swan, M, Hathaway, K, Hogg, C, McCauley, R and Vollrath, R. 2010. Citizen science genomics as a model for crowdsourced preventive medicine research. Journal of Participatory Medicine, 2: e20. DOI: https://doi.org/10.2217/pme.11.97

Talbot, M. 2020. The rogue experimenters. New Yorker, 18 May [online access at https://www.newyorker.com/ magazine/2020/05/25/the-rogue-experimenters last accessed 12 July 2020].

Theisz, K, Couch, J and Gillanders, E. 2016. NIH citizen science working group. Available at https://citscibio.org/resources/31/ download/CS_Working_Group_Intro_rev_4-1-16.pdf (Last accessed 12 July 2020).

Tong, A, Sainsbury, P and Craig, J. 2007. Consolidated criteria for reporting qualitative research (COREQ): A 32-item checklist for interviews and focus groups. International Journal for Quality in Health Care, 19(6): 349-357. DOI: https://doi.org/10.1093/ intqhc/mzm042

Trejo, M, Canfield, I, Robinson, JO and Guerrini, CJ. 2021. How biomedical citizen scientists define what they do: It's all in the name. AJOB Empirical Bioethics, 12(1): 63-70. DOI: https://doi. org/10.1080/23294515.2020.1825139

US Code of Federal Regulations (CFR). 2019. Title 21, parts 50, 56; title 45, part 46 .

Vayena, E and Tasioulas, J. 2013a. Adapting standards: Ethical oversight of participant-led health research. PLOS Medicine, 10(3): e1001402. DOI: https://doi.org/10.1371/journal. pmed.1001402

Vayena, E and Tasioulas, J. 2013b. The ethics of participant-led biomedical research. Nature Biotechnology, 31(9): 786-787. DOI: https://doi.org/10.1038/nbt.2692

Wexler, A. 2017. The social context of "do-it-yourself" brain stimulation: Neurohackers, biohackers, and lifehackers. Frontiers in Human Neuroscience, 11: 224. DOI: https://doi. org/10.3389/fnhum.2017.00224

Wiggins, A and Wilbanks, J. 2019. The rise of citizen science in health and biomedical research. American Journal of Bioethics, 19(8): 3-14. DOI: https://doi.org/10.1080/15265161 2019.1619859

Zarate, OA, Brody, JG, Brown, P, Ramirez-Andreotta, MD, Perovich, L and Matz, J. 2016. Balancing benefits and risks of immortal data: Participants' views of open consent in the Personal Genome Project. The Hastings Center Report, 46(1): 36-45. DOI: https://doi.org/10.1002/hast.523 
TO CITE THIS ARTICLE:

Trejo, M, Canfield, I, Brooks, WB, Pearlman, A and Guerrini, C. 2021. "A Cohort of Pirate Ships”: Biomedical Citizen Scientists' Attitudes Toward Ethical Oversight. Citizen Science: Theory and Practice, 6(1): 15, pp. 1-15. DOI: https://doi.org/10.5334/cstp.360

Submitted: 12 August 2020 Accepted: 12 April 2021 Published: 20 May 2021

COPYRIGHT:

(C) 2021 The Author(s). This is an open-access article distributed under the terms of the Creative Commons Attribution 4.0 International License (CC-BY 4.0), which permits unrestricted use, distribution, and reproduction in any medium, provided the original author and source are credited. See http://creativecommons.org/licenses/by/4.0/.

Citizen Science: Theory and Practice is a peer-reviewed open access journal published by Ubiquity Press.

\section{]u[ ə}

